\title{
Teaching Multiliteracies: A Research Based on Multimodality in a PPT Presentation
}

\author{
Ji Song \\ College English Teaching Department of Dezhou University, Dezhou, China \\ Email: songji126@126.com
}

\begin{abstract}
This paper aims to focus on a research about college students' awareness and level of multiliteracies. The participants in the study are non-English major sophomore undergraduates. They made 267 slides in a 34 PPT presentation works for their assignments. The research shows college students' weak performance in multiliteracies. Thus we have suggested some methods to improve college students' multiliteracies and discussed the instructions the concept of multiliteracies has brought about for college English teachers and learners.
\end{abstract}

Index Terms-multimodality, multiliteracies, PPT

\section{INTRODUCTION}

With the rapid development of science and technology people's ways of communication have changed greatly. According to Kress (2003, p.9-11) four momentous changes are taking place simultaneously which are revolutionizing the landscape of public communication. They are social, economic, communicational and technological changes. In our daily lives we use language, script, picture, images, color, music, sound and some other non-verbal semiotic resources as ways of communication to show what meanings we want to transfer. Compared with enough research in language, people still lack systematical thought on the meaning making of different semiotic resources except for language. Hence in the 1990s researchers in social semiotic circles started to focus on the study of multimodality in such social environment. For example, in an advertisement we may see that the semiotic mode of language and the mode of color are combined together; on the screen script may appear with the modes of music, of color, and of moving image. A11 these mean that all modes bear meaning and therefore are parts of a message. So in such multimodal situation the increasing use of new modes and the new use of old modes in public communication are forcing a reassessment of what literacy is.

\section{Multimodality AND MultiLITERACIES}

Multimodality is a term which is aroused wide concern by linguists and semioticians in recent years in western countries. Van Leeuwen (2005, p.281) holds that Multimodality means the combination of different semiotic modes - for example, language and music - in a communicative artifact or event. Other important representatives, Baldry and Thibault (2006, p.21), added that Multimodality refers to the diverse ways in which a number of distinct semiotic resource systems are both co-deployed and co-contextualized in the making of a text-specific meaning. From the definitions we can see that multimodality is the study of interrelationships and interdependence between different communicative modes, no matter whether they are written or oral, visual or auditory. It is also a way to transcribe the meaning of discourses composed of different semiotic modes. Multimodality does not designate a pre-given entity or text-type. Rather, it is a diversity of meaning making activities that are undergoing rapid change in the current cultural surroundings. What's more, the concept of multimodality is a useful yardstick for measuring and assessing the diversity of ways of meaning making.

For multiliteracies, Cope and Kalantzis (2000, p.5-9) have made a detailed explanation about them. Traditionally literacy pedagogy has meant teaching and learning to read and write in page-bound, official, standard forms of the national language, or in other words, formalized, mono-lingual, mono-cultural, and rule-governed forms of language. But now literacy teaching and learning include a great variety of discourses due to the rapidly social, economic, communicational and technological changes in the contemporary cultural context. So the current literacy has to explain the increasing variety of text forms associated with information and multimedia technologies such as visual images and their relationship to the written word. Under such circumstances the word "multiliteracies" was agreed upon. It was proposed by the New London Group in a conference for discussion about the future of literacy teaching and learning in 1994. The New London Group, a group of linguists including Norman Fairclough, James Gee, Gunther Kress, etc., says the word "multiliteracies" describes two important dimensions: one is the great variety of communication channels and media; the other is the increasing salience of cultural and linguistic diversity. For the first statement, it means meaning is made in ways that are increasingly multimodal, such as, on the web pages, script modes of meaning are combined with audio, video, and spatial modes to make meaning. When new technologies are developing so quickly, we need to 
think about the new ways of meaning making. But to find out ways of meaning making requires a new multimodal literacy. For the second statement, it means with the globalization and wide impact in cross-cultural communication, English is breaking into multiple and increasingly differentiated English marked by accent, national origin, and sub-cultural style and so on, for example, Australian English, New Zealand English, Indian English or even Chinese English.

After the pilot origination of the New London Group, the concept of multiliteracies has aroused a widespread academic interest. For instance, Anderson, Johnson, Joy and Minranda have studied multiliteracies and its relationship with cooperative learning. They have suggested many different levels of multiliteracies. Spiliotopoulus has also studied adults' online learning and holds that online interaction can help students improve their writing and critical thinking skill and thus develop students' cross-cultural awareness. In China some enthusiasts have started their research about multiliteracies. Hu Zhuanglin and Dong Jia (2006) have done a multimodal discourse analysis on the students' PPT presentation of Renmin University of China on the Australia Culture Festival. Zhu Yongsheng (2008) has analyzed an example in multiliteracies in a western country and its enlightenment for foreign language teaching reform in China. Wang Huiping (2010) showed us a multiliteracies practice in an English reading class and suggested making full use of the multimodal resources beyond written texts. Hu Zhuanglin (2007a) has made a theoretical account of the concept of multiliteracies and believed that the mono-modal literacy focused on reading and writing is far from enough in the multimedia setting. We should not only develop learners' traditional literacy, but practice and improve their multiliteracies. He found that the concept of multiliteracies carries two levels of meanings: one is the awareness of multiliteracies; the other is the ability of multiliteracies which includes cultural literacy and technological literacy. As for technological literacy, he argues that it is a kind of multimodal literacy which means learners are able to study, work and represent in the current information environment.

\section{A PRACTICAL RESEARCH}

Hu Zhuanglin and Dong Jia (2006, p.8) hold that one of the ways to test people's awareness and level of multiliteracies is to see whether they are familiar with the new types of multimodal electronic technology. Based on this opinion, we have taken college students' PPT presentation as data to analyze college students' awareness and level of multiliteracies. In order to do this study, we give students PPT presentation assignment. The title is How to Prepare for Going to University, which is based on Unit 1, Book 3, New Standard College English Real Communication Listening and Speaking. The publishing house of the book is Foreign Language Teaching and Research Press in Beijing. The task is, for each group (10 to 12 students), they should finish one PPT by answering following questions:

-What's the best way you prepare academically before going to study at university?

-How is the social side of university life different from school life?

-How do you prepare for the "culture shock" of going to university?

-What challenges do students face when starting university?

.How can you overcome these challenges?

There are altogether 34 students' PPT presentation works from the three classes we teach. All students are non-English major sophomore undergraduates in a college in Dezhou, Shandong Province. Class 1 major in nursing, Class 2 textile engineering and environmental engineering, Class 3 accounting. There are 267 slides in the 34 PPT presentation works. The longest piece of work is the one from Class 2 which includes 17 slides. The shortest one is from Class 3 and has only 5 slides. The average length of all PPT presentation works is about 8 slides.

According to Hu Zhuanglin (2007b, p.4-5) there are four types of genre in PPT discourse. They are prompting genre, visualizing genre, analyzing genre and persuading genre. For the genre of prompting type, Hu Zhuanglin explains that it is a kind of bullet point which helps PPT presenters to organize their thoughts. For instance, Fig. 1 shown below is a typical example from Class 1 . There are 4 bullet points which clearly show the presenter's ideas.

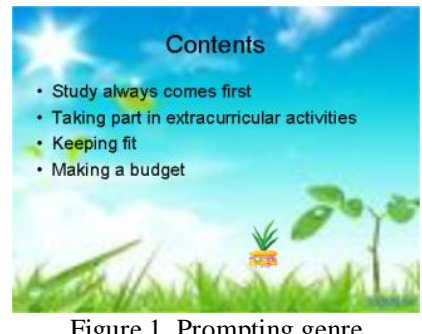

Figure 1. Prompting genre

The characteristic of visualizing genre is to present the idea by means of pictures. Fig. 2 below from Class 3 shows the scene that a student is studying on campus, which clearly tells us what we should do for going to university. 


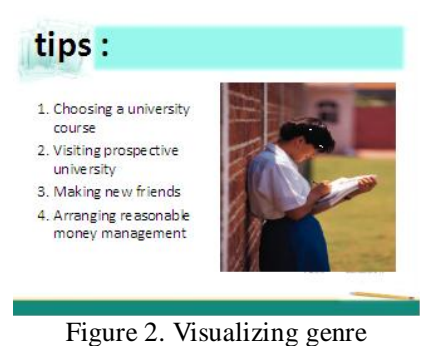

The third one is analyzing genre. The characteristic of which is to use tables or graphs to analyze meaning. Fig. 3 from Class 3 shows such type of genre.

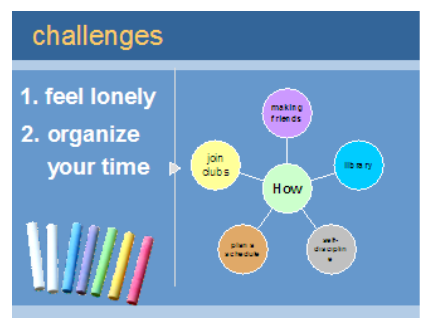

Figure 3. Analyzing genre

For the last type of genre, it is through color, cartoon and music that make spectators know the meaning of the PPT work and realize the presenters' purpose of persuading. Fig. 4 from Class 2 is a good example.

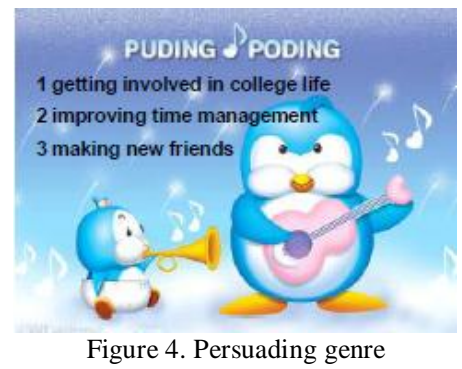

Hu Zhuanglin (2007b, p.5) argues that there are mainly two types of mode in PPT discourse: audio mode and visual mode. The former includes music or sound; the latter includes bullet points, images, graphs and color. In total PPT works, almost all groups have used visual mode, but only five ones have used audio mode. For audio mode, 2 groups choose foreign pop songs (one on the first page and another on the last page), 2 groups light music (always on the first page) and 1 group the sounds of hands-clapping (on the last page).

There are generally three types of visual mode. The first one is verbal mode. For instance, there is one slide from Class 3 in which the group mainly uses verbal mode to explain that students should make a balance between study and community activities. See Fig. 5 below.

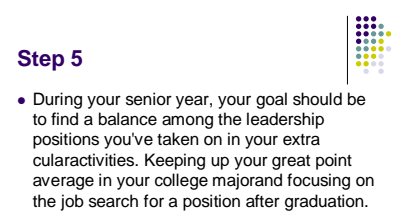

Figure 5. Verbal mode

The second one is the combination of the mode of image and the mode of language. We can take the slide of Fig. 6 for example. It shows that youngsters call their parents in a telephone booth or in a cybercafé. See Fig. 6 below. 


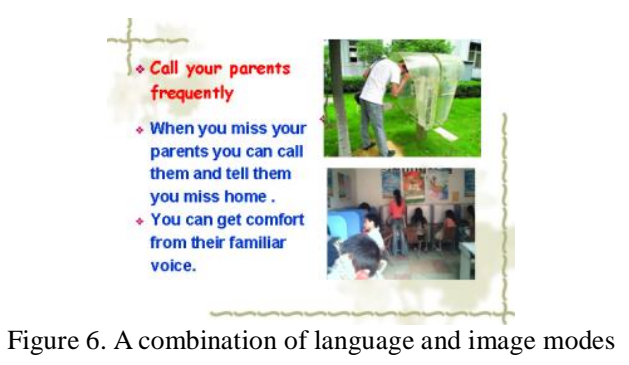

The third one is the mode of image. Some students prefer to use image to express meaning. For example, one slide from Class 2 uses the image to explain that parents make great efforts to send their child to go to university. See Fig. 7 below.

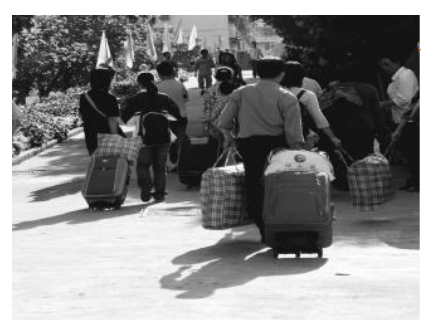

Figure 7. Image mode

\section{Features of PPT PResentation}

First, the wide use of persuading genre and visualizing genre is one of the features of students' PPT presentation. Among the 267 slides in students' PPT presentation works, there are 136 that are persuading genres, which account for $51 \%$ of the total slides; there are 114 that are visualizing genres, which account for $43 \%$ of the total slides. Only 17 pieces of them are prompting and analyzing genres, which account for $6 \%$ of the total.

Then, the modes of language and image are students' major modes of communication. From all the PPT slides the students made we can see that the mode of language is students' first chosen mode of communication. But instead of using "some subordinate clauses" (Hu Zhuanglin \& Dong Jia 2006, p.8), the students use many paragraphs to express meaning. Besides, the mode of image is also very much favored by the students. So we can say that the mode of language and mode of image are students' two main and most favorable modes to express meaning of communication in their PPT presentation.

Next, the students lack clear awareness of making reasonable use of other semiotic modes other than language and image. In order to attract audience's attention, the mode of color is also often used to express meaning. But students are very arbitrary use of color because we have found that their use of color is not highly relevant to their meaning making and even sometimes it causes ambiguity. Besides, the students don't make full use of other semiotic resources such as typeface, lining, framing, etc.

At last, the limited source of information is also a characteristic of the students' PPT presentation. Because the topic of the task is concerned with campus life, a lot of groups select the same series of pictures of our college. And we have also found that there is much repetition of contents in students' PPT presentation. So we can say that college students' awareness and level of multiliteracies need to be improved.

\section{Suggestions FOr IMPROVing Multiliteracies}

At the beginning, technological guidance is the most important thing for learners. One of the key points of multiliteracies is technological literacy, that is to say, multimodal literacy. So we can take information technology, such as the making of PPT and some other practical computer knowledge, into learners' study of compulsory courses to try to improve their skills.

Then lecture is another effective way to raise learners' multiliteracies. We can give lectures about culture and language to let students recognize the changes in public communication. Meanwhile, we should notice that all semiotic resources can be used to make meaning in current culturally diverse social context other than language and script, because various modes have different potentials and limitations.

In the end, training is always the best method for learners to practice their literacy. At the same time, teachers should try to give students such kind of assignment regularly so that they will be familiar with the technique of multimodal meaning making and presenting. By this way learners' awareness and level of multiliteracies can be perfected.

\section{INSTRUCTIONS TO TEACHERS AND LEARNERS}


Since the concept of multiliteracies is so important in contemporary communication context, as teachers, we have responsibility to consider the connotation suggested by the idea of multiliteracies. We think the notion of multiliteracies will bring about a lot of instructions to English teachers and learners.

On one hand, the important task of education is to ensure that all students benefit from learning so that they can fully take part in public community and economic life. And literacy education is expected to play a very important role in fulfilling this mission. So as English teachers, we must think over how to make sure the educational success with the increasing variety of language, culture, and technology. In other words, what should be taught for literacy in the future in the contemporary diverse cultural situation? The answer is absolutely certain till now, but probably we can get a little hint from one word-design, a concept created by the New London Group for the "what" of literacy pedagogy in the future. In this way we can not only improve students' literacy for reading and writing, but also teach students' multiliteracies for reading audio, visual, spatial, gestural and multimodal designs. We definitely believe that a multimodal educational tendency will be beneficial for all learners.

As learners, we have to be exposed ourselves to the new changes and to actively participate in the new social practices. In our daily lives, we can see whether in newspapers, magazines or web pages most texts are multimodal ones which involve complex interaction with written text, images and other graphic or sound modes. But the skill of producing multimodal texts of this kind will not be taught in schools or colleges. If we neglect the development of this new communication ability or "new literacy", a new generation of being illiterate will be produced. Moreover we will not be able to express meaning effectively without the awareness of multiliteracies. So only when we have grasped mulitiliteracies can we do our job much better and live a more healthy life efficiently.

\section{CONCLUSION}

By now we can say that our students tend to use persuading genre and visualizing genre instead of other types of genre to make meaning in their PPT presentation. Moreover, the mode of language and the mode of image are their favorite modes of communication. But the use of sound, color and other semiotic resources are very arbitrary so that no obvious coherent effects can be made. Meanwhile, the learners' sources for knowledge are very limited. All of these reveal that they are not familiar with multimodal literacy; therefore they can not make best and full use of technological means to create meaning. The concept of multiliteracies is still in its early stages. And the study we have finished is also very simple. But the idea of mutiliteracies is a beginning of a new way of thinking and there is much research about multiliteracies which are worth doing for us. The purpose for teaching multiliteracies is to try to make learners develop an ability of using visual semiotics to express meanings in business or academic communication and make them become successful meaning makers in the current cross-cultural situation.

\section{REFERENCES}

[1] Baldry, A. \& Thibault, P.J. (2006). Multimodal Transcription and Text Analysis. London: Equinox.

[2] Cope, B. \& Kalantzis, M. (2000). Multiliteracies: Literacy Learning and the Design of Social Futures. London: Rouledge.

[3] Hu Zhuanglin. (2007a). Multimodalization in Social Semiotics. Language Teaching and Linguistic Studies, 168(1), 1-10.

[4] Hu Zhuanglin. (2007b). PowerPoint: Tool, Text, Genre and Style. Foreign Language Education, 28(4), 4-5.

[5] Hu Zhuanglin, Dong Jia. (2006). Multimodal Construction of Meaning. CAFLE, 109(3), 8.

[6] Kress, G. (2003). Literacy in the New Media Age. London: Rouledge.

[7] Van Leeuwen, T. (2005). Introducing Social Semiotics. London: Rouledge.

[8] Wang Huiping. (2010). The Development of Multiliteracies in English Reading Instruction. Foreign Language World, 140(5), 20-25.

[9] Zhu Yongsheng. (2008). Multiliteracy Research and Its Impact on Teaching Reform in China. Foreign Languages Research, $110(4), 10-14$.

Ji Song was born in Baoqing, Heilongjiang Province, China in 1972. He received his M.A. degree in applied linguistics from China University of Petroleum, China in 2006.

$\mathrm{He}$ is currently a lecturer in College English Teaching Department of Dezhou University, Dezhou, China. His research interests include CALL, multimodal discourse analysis and multimodal metaphor. 